\title{
Focus on lung cancer screening
}

\author{
Alfredo Tartarone ${ }^{1}$, Rosa Lerose ${ }^{2}$, Michele Aieta $^{1}$ \\ ${ }^{1}$ Department of Onco-Hematology, Division of Medical Oncology, ${ }^{2}$ Hospital Pharmacy, IRCCS-CROB Referral Cancer Center of Basilicata, \\ Rionero in Vulture (PZ), Italy \\ Contributions: (I) Conception and design: A Tartarone; (II) Administrative support: None; (III) Provision of study materials or patients: None; (IV) \\ Collection and assembly of data: None; (V) Data analysis and interpretation: None; (VI) Manuscript writing: All authors; (VII) Final approval of \\ manuscript: All authors. \\ Correspondence to: Dr. Alfredo Tartarone. Department of Onco-Hematology, Division of Medical Oncology, IRCCS-CROB Referral Cancer Center \\ of Basilicata via Padre Pio 1, 85028 Rionero in Vulture (PZ), Italy. Email: tarta1@virgilio.it.
}

\begin{abstract}
Poor survival of lung cancer (LC) patients depends on several factors first of all the delay in the diagnosis, considering that the majority of patients have an advanced-stage disease at the time of diagnosis. In this context, use of screening to increase the percentage of early LC detection can play a crucial role. After the preliminary unsatisfactory experiences with chest X-rays and sputum cytology, low dose computed tomography (LDCT) has become the best method for LC screening. In particular, several randomized LDCT screening trials conducted in the last year showed significant reductions in LC mortality in high-risk subjects. This review focuses on both recent advances in LC screening and some open questions.
\end{abstract}

Keywords: Non-small cell lung cancer (NSCLC); lung cancer screening (LC screening); low dose computed tomography (LDCT)

Submitted Jan 30, 2020. Accepted for publication Feb 23, 2020.

doi: $10.21037 /$ jtd.2020.02.17

View this article at: http://dx.doi.org/10.21037/jtd.2020.02.17

\section{Introduction}

Despite the recent advances occurred in the therapy of non-small cell lung cancer (NSCLC) the overall survival (OS) still remains unsatisfactory, since for patients with localized NSCLC the overall 5 -year survival rate is about $60 \%$, while for patients with metastatic disease the 5 -year survival rate is less of $10 \%$ (1). Poor survival depends on several factors first of all the delay in the diagnosis, considering that the majority of patients have an advancedstage disease at the time of diagnosis. In this context, use of screening to increase the percentage of early LC detection can play a crucial role. After the preliminary unsatisfactory experiences with chest $\mathrm{X}$-rays and sputum cytology, low dose computed tomography (LDCT) has become the best method for LC screening. As we shall see later, since 2011 several large randomized trials on LDCT screening showed significant reductions in LC mortality in high-risk subjects $(2-5)$. These data were confirmed by a meta-analysis of randomised LDCT screening trials that reported an overall lung cancer (LC) mortality reduction of $20 \%$ connected to the early cancer detection (6).Therefore, the United States Preventive Services Task Force (USPSTF) recommended annual screening with LDCT in adults aged 55 to 80 years, current and former smokers (quit $<15$ years) who smoked 30 or more pack-years ("USPSTF criteria") (7). Several scientific associations, including the American Society of Clinical Oncology (ASCO), the National Comprehensive Cancer Network (NCCN) and the European Society of Medical Oncology (ESMO), developed recommendations for LC screening using LDCT in high risk subjects (8-10).

On this basis, the implementation of LC screening, as well as anti-smoking campaigns, can play a crucial role in the battle against $\mathrm{LC}$.

\section{LC screening studies}

In view of the encouraging results observed in pilot or small randomized studies (11-16) the effectiveness of LDCT screening has been investigated by several large randomized 
Table 1 Main randomised studies

\begin{tabular}{|c|c|c|c|}
\hline Study & Population & Number of cases & Lung cancer mortality \\
\hline NELSON, EU (3) & $\begin{array}{l}\text { Age } 50-75 \text { years; who had smoked } \geq 15 \mathrm{cig} / \mathrm{d} \text { for } \geq 25 \text { years or } \geq 10 \mathrm{cig} / \mathrm{d} \text { for } \\
\geq 30 \text { years, current/former smokers with cessation } \leq 10 \text { years }\end{array}$ & 15,792 & $-26 \%$ \\
\hline MILD, IT (4) & $\begin{array}{l}\text { Age } 49-75 \text { years; } \geq 20 \text { pack-years, current/former smokers with cessation } \\
\leq 10 \text { years }\end{array}$ & 4,099 & $-39 \%$ \\
\hline
\end{tabular}

trials including the US National Lung Cancer Screening Trial (NLST), the Dutch-Belgian Nederlands Leuvens Longkanker Screenings Onderzoek (NELSON) trial and the Multicentric Italian Lung Detection (MILD) trial (2-4) (Table 1).

From August 2002 to April 2004 the NLST trial enrolled in U.S. more than 50,000 people at high risk for LC that were randomized to receive three annual screening with either LDCT or chest X-rays (2). In this trial any noncalcified nodule measuring at least $4 \mathrm{~mm}$ in any diameter and radiographic images of non-calcified nodule or mass were classified as positive/suspicious for LC. The NLST was the first LC screening study to demonstrate a reduction in LC mortality showing a $20 \%$ reduction in LC mortality and a $6.7 \%$ reduction from any cause of death.

The subsequent European NELSON trial enrolled into a screening group and a control group more than 15,000 current or former smokers, who were considered at high risk for LC based on the answers provided to a specific questionnaire (3). Participants included in the screening arm received a LDCT at baseline, 1, 3, and 5.5 years after randomization. In this trial nodule volume was generated semiautomatically by LungCare software and lung nodules categorization was based on size, characteristics and growth rate (17). In particular, any non-calcified nodule with a solid component $>500 \mathrm{~mm}^{3}$ ( $>9.8 \mathrm{~mm}$ in diameter) was classified as positive for LC (18). Results of the NELSON trial confirmed the value of LDCT screening in people at high risk for developing LC showing a $26 \%$ reduction in LC mortality in men and a larger reduction in the smaller subset of women over a 10 -year period. Notably, about $50 \%$ of the cancers diagnosed in the screening arm were early stage, while the majority of cancers in the control arm were in an advanced stage at diagnosis. About the rounds of repeat screening, the 2.5 -year interval in the fourth round resulted in an increased LC detection respect to the previous rounds (19).
There are some differences between the previously reported two trials: first, participants in the NELSON control group received no screening instead of chest radiography as in the NLST trial; second, the NELSON trial provided LDCT screening at baseline (round 1), after one year (round 2), after 3 years (round 3) then after 5.5 years (round 4 ), while in the NLST trial there were three annual screenings; third, the NELSON trial evaluated the nodule volume and volume doubling time (VDT), while the NLST considered only the nodule diameter.

The MILD trial randomized more than 4,000 current or former smokers of $\geq 20$ pack-years to a screening arm with further randomization to annual or biennial LDCT or to a control arm without intervention for a median period of 6 years (4-6). Baseline LDCT was considered as negative for individuals without non-calcified nodules or with volume $<60 \mathrm{~mm}^{3}$, indeterminate for non-calcified nodules of 60 $250 \mathrm{~mm}^{3}$ and positive for non-calcified nodules $>250 \mathrm{~mm}^{3}$. The MILD trial showed that prolonged screening over 5 years reduces 10 -year mortality (39\% reduction of LC mortality and $20 \%$ reduction of overall mortality) and that biennial LDCT after a negative baseline assessment doesn't compromise the efficacy of the screening (4-6).

Recently, at the 2019 World Conference on Lung Cancer (WCLC) the same Italian researchers presented the preliminary results of the BioMILD trial, which tested the utility of combined blood microRNA testing and LDCT screening to predict the individual LC risk (20). The diagnostic performance of a plasma microRNA signature classifier (MSC) was previously evaluated in samples collected from smokers included in the MILD trial (21). This validation trial demonstrated that MSC has predictive, diagnostic and prognostic value and that combination of both MSC and LDCT can reduce the LDCT false positive rate (21). The BioMILD trial enrolled more than 4,000 volunteers current/former smokers with a median age of 60 years (Figure 1). The Italian researchers classified 


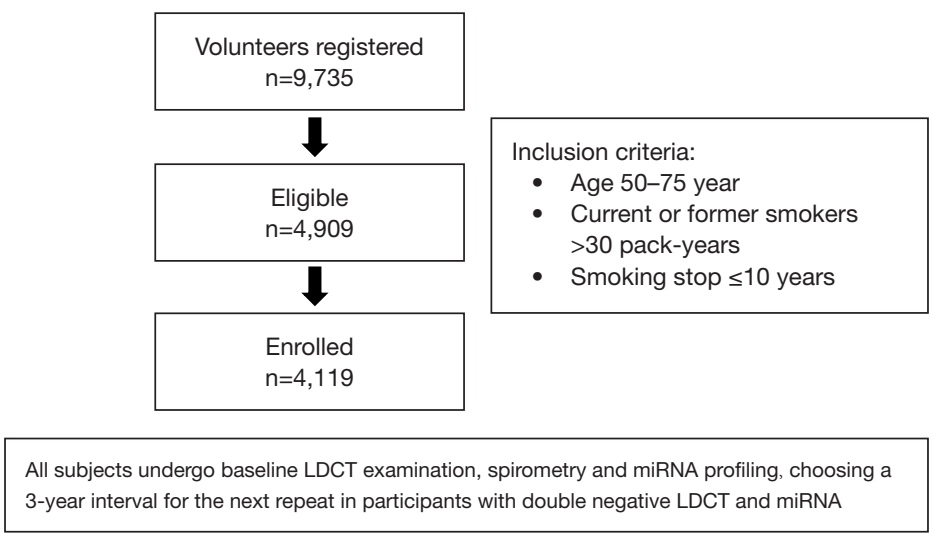

Figure 1 The BioMILD Trial. LDCT, low dose computed tomography.

Table 2 Lung cancer screening with low dose computed tomography: open questions

How cost-effective is a lung cancer screening program?

What are the risks associated with over-diagnosis, further diagnostic testing, long-term accumulation of radiation exposure?

Is there a consensus about the definition of high-risk subjects?

What is the optimal duration of screening and the screening intervals?

Are we ready to transfer in clinical practice a multi-screening approach integrating imaging technique and biomarkers?

participants into three risk groups and chosen different screening intervals for the following repeats according to their testing results; going more in detail, 2,384 participants (58\%) with double negative LDCT and miRNA were sent to a 3-year interval, 1,526 (37\%) with positive miRNA or indeterminate/positive LDCT (single positive) and 209 (5\%) with positive miRNA and indeterminate/positive LDCT (double positive) were sent to annual or shorter LDCT repeat. In this trial LC incidence at 4 years resulted significantly higher among patients with single-positive results (HR 5.96; 95\% CI, 3.38-10.52) or double-positive results (HR 36.64; 95\% CI, 20.31-66.11) compared with the double-negative group. Similarly risk for mortality at 4 years was much higher for the single-positive (HR 4.67; 95\% CI, 1.26-17.24) and double-positive (HR 32.24; 95\% CI, 8.55-121.6) groups than for the double-negative group. The authors concluded that the combination of microRNA assay and LDCT is a useful tool for evaluating the individual risk profile and to avoid unnecessary CT scans.

In a large Chinese study, including 6,717 participants randomly assigned to a screening group or a control group, the results of the baseline screening showed a $74.1 \%$ increase in detecting early-stage LC with LDCT (22). The China Lung Cancer Screening (CLUS) study version 2.0
(NCT03975504), that was designed to validate previous findings and optimize the screening procedure, is actually ongoing.

A recent meta-analysis including the main randomized LDCT screening trials, reported a pooled estimate for LC mortality of 0.80 (95\% CI, $0.71-0.90)$ and of $0.94(95 \%$ CI, 0.89-1.00) for all cause of mortality (6). The incidence of LC was higher in the LDCT arm with a more frequent detection of early stage LC, as well as adenocarcinomas (6).

\section{Open questions and closing remarks}

Although LDCT screening has been shown to reduce LC mortality, several questions are still open, as reported in Table 2. The optimal duration of screening as well as the screening intervals have been the subject of debate for long time. Regarding the optimal screening intervals the MILD trial showed that biennial screening achieves a decrease in LC mortality similar to annual LDCT in participants with negative baseline assessment, while the BioMILD trial demonstrated that the combination of microRNA assay and LDCT can be an useful tool for evaluating the individual risk profile and to avoid unnecessary LDCT repeats $(5,20)$. About the duration of screening, the recent 
Table 3 European Union position statement recommendations on LC screening (25)

LDCT is the only method for the early detection of LC that has been shown to provide a mortality reduction

A risk stratification approach should be used for future LDCT LC screening programmes

Smoking cessation should be offered to all current smokers included in a LC screening

Management of the detected solid nodules should include semi-automatically measured volume and VDT

National quality assurance boards should be set up to oversee technical standards

A lung nodule management pathway should be established and incorporated into clinical practice

Non-calcified baseline lung nodules greater than $300 \mathrm{~mm}^{3}$ and new lung nodules greater than $200 \mathrm{~mm}^{3}$ should be managed in

multidisciplinary teams

European countries need to set a timeline for implementing LC screening

LC, lung cancer; LDCT, low dose computed tomography; VDT, volume doubling time.

meta-analysis published by Rota et al. reported, as well as also showed by the MILD trial, a greater reduction both of LC mortality and all-cause mortality beyond the fifth year of screening $(5,6)$; therefore, these findings seem to suggest that campaigns of screening should be extended over long periods of time (6). Estimating the risk of cancer associated with low-dose radiation exposure represents another contentious issue. McCunney et al. reported that radiation exposure from LDCT screening and diagnostic procedures could exceed the lifetime dose experienced by nuclear power workers and atomic bomb survivors (23). Rampinelli et al., conversely, observed that the benefit of LC screening in terms of mortality reduction outweighs the risks associated with long-term accumulation of radiation exposure (24). Anyway, the recent progress in CT technology certainly can further decrease the radiation risk for LC screening participants.

A recent European position statement on LC screening identified a list of specific actions to adopt before of new campaigns of screening (25) (Table 3). This position paper recommends, among other things: that the evaluation of the detected solid nodules should include a semi-automatically measured volume and VDT, that detected solid nodules should be managed in a multidisciplinary team and that smoking cessation should be proposed to the current smokers included in a LC screening. As regards the latter point, Pastorino et al. demonstrated that quitting smoking significantly reduce the overall mortality of smokers enrolled in two LDCT screening programs (26).

\section{Conclusions}

In conclusion, LDCT represents the only method for the early detection of LC that has been shown to provide a mortality reduction; however, although LDCT screening is already available in some countries, its large-scale implementation has not yet taken place. In the near future, a multi-screening approach integrating imaging technique and novel biomarkers, as suggested by the results of the BioMILD trial, could ameliorate the assessment of the individual LC risk and reduce unnecessary LDCT repeats. Anyway, the best strategy to further reduce mortality should provide for the implementation of both LC screening programmes and anti-smoking campaigns.

\section{Acknowledgments}

The authors thank Marina Tartarone for English editing. Funding: None.

\section{Footnote}

Provenance and Peer Review: This article was commissioned by the Guest Editor (Alfredo Tartarone) for the Series "Improving Outcomes in Lung Cancer Through Early Diagnosis and Smoking Cessation" published in fournal of Thoracic Disease. The article was sent for external peer review organized by the Guest Editor and the editorial office.

Conflicts of Interest: All authors have completed the ICMJE uniform disclosure form (available at http://dx.doi. org/10.21037/jtd.2020.02.17). The series "Improving Outcomes in Lung Cancer Through Early Diagnosis and Smoking Cessation" was commissioned by the editorial office without any funding or sponsorship. AT served as the 
unpaid Guest Editor of the series and serves as an unpaid editorial board member of Fournal of Thoracic Disease from Aug 2019 to Jul 2021. The authors have no other conflicts of interest to declare.

Ethical Statement: The authors are accountable for all aspects of the work in ensuring that questions related to the accuracy or integrity of any part of the work are appropriately investigated and resolved.

Open Access Statement: This is an Open Access article distributed in accordance with the Creative Commons Attribution-NonCommercial-NoDerivs 4.0 International License (CC BY-NC-ND 4.0), which permits the noncommercial replication and distribution of the article with the strict proviso that no changes or edits are made and the original work is properly cited (including links to both the formal publication through the relevant DOI and the license). See: https://creativecommons.org/licenses/by-nc-nd/4.0/.

\section{References}

1. Lung Cancer Survival Rates. Available online: http:// www.cancer.org/cancer/lung-cancer/detection-diagnosisstaging/survival-rates.html

2. Aberle DR, Adams AM, Berg CD, et al. National Lung Screening Trial Research Team. Reduced lung-cancer mortality with low-dose computed tomographic screening. N Engl J Med 2011;365:395-409.

3. De Koning H, van Der Aalst C, Ten Haaf K, et al. Effects of volume CT lung cancer screening. Mortality results of the NELSON randomized-controlled population based trial. J Thorac Oncol 2018;13:S185.

4. Pastorino U, Silva M, Sestini S, et al. Prolonged lung cancer screening reduced 10-year mortality in the MILD trial: new confirmation of lung cancer screening efficacy. Ann Oncol 2019;30:1162-9.

5. Pastorino U, Sverzellati N, Sestini S, et al. Ten-year results of the multicentric Italian lung detection trial demonstrate the safety and efficacy of biennial lung cancer screening. Eur J Cancer 2019;118:142-8.

6. Rota M, Pizzato M, La Vecchia C, et al. Efficacy of lung cancer screening appears to increase with prolonged intervention: results from the MILD trial and a metaanalysis. Ann Oncol 2019;30:1040-3.

7. Moyer VA, U.S. Preventive Services Task Force. Screening for lung cancer: U.S. Preventive Services Task Force recommendation statement. Ann Intern Med
2014;160:330-8.

8. Bach PB, Mirkin JN, Oliver TK, et al. Benefits and harms of CT screening for lung cancer: a systematic review. JAMA 2012;307:2418-29.

9. Wood DE, Kazerooni EA, Baum SL, et al. Lung Cancer Screening, Version 3.2018, NCCN Clinical Practice Guidelines in Oncology. J Natl Compr Canc Netw 2018;16:412-41.

10. Postmus PE, Kerr KM, Oudkerk M, et al. Early and locally advanced non-small-cell lung cancer (NSCLC): ESMO Clinical Practice Guidelines for diagnosis, treatment and follow-up. Ann Oncol 2017;28:iv1-21.

11. Blanchon T, Brechot JM, Grenier PA, et al. Baseline results of the DEPISCAN study: a French randomized pilot trial of lung cancer screening comparing low dose CT scan (LDCT) and chest X-ray (CXR). Lung Cancer 2007;58:50-8.

12. Field JK, Duffy SW, Baldwin DR, et al. The UK Lung Cancer Screening Trial: a pilot randomized controlled trial of low-dose computed tomography screening for the early detection of lung cancer. Health Technol Assess 2016;20:1-146.

13. Paci E, Puliti D, Lopes Pegna A, et al. Mortality, survival and incidence rates in the ITALUNG randomized lung cancer screening trial. Thorax 2017;72:825-31.

14. Infante M, Cavuto S, Lutman FR, et al. Long-term followup results of the DANTE trial, a randomized study of lung cancer screening with spiral computed tomography. Am J Resp Crit Care Med 2015;191:1166-75.

15. Wille MM, Dirksen A, Ashraf H, et al. Results of the randomized Danish lung cancer screening trial with focus on high-risk profiling. Am J Resp Crit Care Med 2016;193:542-51.

16. Becker N, Montsch E, Gross ML, et al. Randomized study on early detection of lung cancer with MSCT in Germany results of the first 3 years of follow-up after randomization. J Thorac Oncol 2015;10:890-96.

17. Ru Zhao Y, Xie X, de Koning HJ, et al. NELSON lung cancer screening study. Cancer Imaging 2011;11 Spec No A:S79-84.

18. van Klaveren RJ, Oudkerk M, Prokop M, et al. Management of lung nodules detected by volume CT scanning. N Engl J Med 2009;361:2221-9.

19. Yousaf-Khan U, van Der Aalst C, de Jong PA, et al. Final screening round of the NELSON lung cancer screening trial: the effect of a 2.5 -year screening interval. Thorax 2017;72:48-56.

20. Pastorino U, Boeri M, Sestini S, et al. Blood microRNA 
and LDCT reduce unnecessary LDCT repeats in lung cancer screening: results of prospective BioMILD trial. J Thorac Oncol 2019;14:S5-6.

21. Sozzi G, Boeri M, Rossi M, et al. Clinical utility of a plasma-based miRNA signature classifier within computed tomography lung cancer screening: a correlative MILD trial study. J Clin Oncol 2014;32:768-73.

22. Yang W, Quian F, Teng J, et al. Community-based lung cancer screening with low-dose CT in China: results of the baseline screening. Lung Cancer 2018;117:20-6.

23. McCunney RJ, Li J. Radiation risks in lung cancer

Cite this article as: Tartarone A, Lerose R, Aieta M. Focus on lung cancer screening. J Thorac Dis 2020;12(7):3815-3820. doi: $10.21037 /$ jtd.2020.02.17 screening programs. Chest 2014;145:618-24.

24. Rampinelli C, De Marco P, Bellomi M. Radiation risk from lung cancer screening. Ann Transl Med 2017;5:480.

25. Oudkerk M, Devaraj A, Vliegenthart R, et al. European position statement on lung cancer screening. Lancet Oncol 2017;18:e754-66.

26. Pastorino U, Boffi R, Marchianò A, et al. Stopping smoking reduces mortality in low-dose computed tomography screening participants. J Thorac Oncol 2016;11:693-9. 